The disadvantage of this arrangement is that the student who is reading the book in an orderly manner needs to refer to later chapters with which he is as yet unfamiliar, but this is a small criticism. The text is clear and the illustrations, which include many new ones, extremely good. No attempt has been made to give the technical details of operations; these are unnecessary for the undergraduate and for him the book can be thoroughly recommended. The postgraduate will need to augment it from other sources, but he, too, will find it a valuable mine of information.

\section{Osteochondritis Dissecans}

I. S. Smillie. Pp. viii +224 , illustrated. Edinburgh and London: E. \& S. Livingstone. 1960. 60s.

The word 'osteochondritis' is etymologically unsatisfactory and pathologically confusing. The student tends to shrug his shoulders hopelessly when he finds that in different parts of the body 'osteochondritis' appears to have different meanings, and nowhere does it mean what it says. This difficult subject has been studied by Mr. Smillie for many years and he now presents his views, including observations on 300 cases.

He divides the book into two parts: (I) Etiology and Pathology, and (2) Clinical Features and Treatment. His efforts at clarifying are admirable but the style is somewhat turgid. Many sentences are cumbrous and unwieldy, requiring re-reading before their meaning is clear; even the headings may occupy several lines and, because they advance on a broad front, lose the sharpness of their impact. Perhaps this presentation is deliberate, designed to compel a second reading of each important statement.

The author has been well served by his publishers who have used paper of the highest quality and beautifully clear type. The numerous radiographs, clinical photographs and diagrams are splendidly reproduced. The modern view that operation photographs demand colour has been accepted, and the number of colour photographs must have added considerably to the cost of production; it is a pity that several look blurred or show faulty colour rendering.

The shortcomings of the book are trivial, its value considerable. The reader should not expect the whole of a difficult and complex subject to click into place, but he can rely on finding the book an authoritative and fascinating work of reference.

\section{Stroke: A Diary of Recovery}

Douglas Ritchie. Pp. 174. London: Faber and Faber. 1960. 12s. $6 d$.

Opinions will differ about this book, not because doctors and patients obviously differ from each other and among themselves, but because the impact which it makes upon the reader will vary according to his experience, his practice and his mood. I was in the mood. I began reading it the week after a new patient of mine was similarly affected.

Douglas Ritchie held up, as it were, a mirror for me to see what I looked like in my new patient's eyes, since she was no longer able to tell me herself. He helped me to help her. He will help others, aphasics or talkers, if they are in the mood to read a penetrating analysis of incomplete recovery.
The student who reads this book will realize how little he has been taught of life outside hospital, where all but a few weeks of this journey to recovery took place. The young doctor meeting Douglas Ritchie, 'Col. Britton', or his like will have not only more sympathy but more facts to go on. It is likely, however, that the most appreciative opinions will come from older practitioners who have struggled with themselves, as well as for their patients, on roads that have not always led even to partial recovery.

Highlights among the lessons for all-doctor, aphasic, and relative alike-are: the futility of 'baby talk' by onlookers; the frustration caused by unfamiliar people and surroundings, particularly in hospital; the difficulty $\frac{1}{\infty}$ of dealing with unfamiliar necessities that require speech more than gesture; sepsis of insensitive skin; how slow $\vec{\circ}$ the dawn of realization that all is not well with mind and body; the value and limitations of the "twenty questions' technique for conversations, jokes and urgent business; the need for long visits early in the illness and for prompt visits on handing over between doctors; the difficulty of concentration, which reduces the value of television and wireless below the onlooker's expectation; the emotional element of a stroke and a stroke of the $\vec{N}$ emotions; the need for those with speech to take time $\mathrm{N}$ to find out if the aphasic has something urgent to ask or iN 'talk about' and for patience to find out what; the need $\mathfrak{N}$ for two-sided not one-sided interviews, 'checkups' and $\frac{1}{\sigma}$ discussions with an aphasic. 'But knowledge is nearly always better than ignorance, for anyone, for patients as for doctors'.

This is a slightly difficult book to get through or to put down. Read it and see what you think.

\section{A Laboratory Handbook of Blood Transfusion Techniques}

A. Derek Farr, F.I.M.L.T., A.I.S.T. Pp. xi +13 illustrated. London: William Heinemann Medicat Books. 1961. 17s. $6 d$.

This little book, written by a senior technician in the National Blood Transfusion Service, describes in detail aspects concerned with the preparation and storage of $Q$ blood and blood products, that had not been included $\overrightarrow{\vec{O}}$ in previous textbooks. In the various chapters he $\frac{\partial}{3}$ deals with the apparatus used by a blood transfusion $\bar{\partial}$ service, the preparation and storage of the anticoagulant crystalloid solutions, the operation of a blood bank and other points concerned in the preparation of whole blood for transfusion.

He also mentions the various blood products and finally writes briefly on blood volume expanders and on the preparation of transfusion apparatus, including the newer plastic taking and giving sets.

The author deliberately touches only briefly on the serological aspects of his subject as these are fully $ᄋ$ covered in many other works. A number of good diagrams and photographs are appropriately used to $\frac{I}{O}$ illustrate the text.

This book undoubtedly fills a gap in this subject and $N$ should prove useful to candidates studying for the final $\sigma$ examination in hæmatology and blood transfusion tech- N niques of the I.M.L.T. It will also be of considerable $\mathrm{N}$ value to trainee pathologists in routine hospital labora- $\omega$ tories who may not have had an opportunity of working in a unit of the National Blood Transfusion Service. 